\title{
Mapping and Analysis of Technology Roadmap of Stem Cell Industry -Taking Industrial Planning and Development of Guangdong Province as An Example
}

\author{
Man Chu ${ }^{1}$, Hongshen Pang*2, Can Lin*3, Xiaochu Qin ${ }^{4}$, Danhui Song ${ }^{2}$, Chen Guo ${ }^{2}$ \\ ${ }^{1}$ Faulty of Medical Technology, Shaanxi University of Chinese Medicine, Xianyang, Shaanxi, China, \\ ${ }^{2}$ Library, Shenzhen University, Shenzhen, Guangdong, China \\ ${ }^{3}$ School of economics, Shenzhen University, Shenzhen, Guangdong, China \\ ${ }^{4}$ Guangzhou Regenerative Medicine and Health Guangdong Laboratory, Guangzhou, Guangdong, China
}

\begin{abstract}
As the most revolutionary technology in cell therapy, stem cell technology will give birth to a series of new biotechnology, drive the development of the pharmaceutical industry, and lead the future of biological economy. Guangdong province has a good foundation for stem cell R\&D and has set up a project named "Stem Cell and Tissue Engineering Technology" to make breakthroughs in core technologies of stem cell research. In this paper, it is of great significance to compile the industrial technology roadmap and clarify the key points of stem cell and tissue engineering industry through the research to provide reference for the decision-making in Guangdong province.
\end{abstract}

\section{INTRODUCTION}

Research on stem cells and tissue engineering is the most popular frontiers in today's life science. Regenerative medicine with stem cell therapy as the core is effective to repair the important organ damage and cure cardiovascular disease, metabolic disease, disease of the nervous system, blood system disease, autoimmune disease and other major diseases. There is likely to be a big leap forward in the research of stem cells in the future. Government and relevant institutions in some countries are constantly adjusting and improving the R\&D strategies and supporting policies of stem cells and tissue engineering, increasing $\mathrm{R} \& \mathrm{D}$ investment and promoting the combination of industry, learning and research.

To master the industrial trends timely and understand the development situation of the stem cell and tissue engineering industry at home and abroad comprehensively, the formulation of the technical roadmap of stem cell and tissue engineering industry in Guangdong provides positive reference.

\section{THE CHARACTERISTICS AND BOUNDARY OF STEM CELL AND TISSUE ENGINEERING INDUSTRY CHAIN}

Stem cell industry refers to the general name of the industry that relies on stem cell collection, storage, research, transplantation, treatment and other products or services to meet various medical and application purposes of human beings. In recent years, the speed of stem cell research and the process of industrialization is accelerated. Europe, USA, South Korea and other developed countries are focusing on areas like stem cell regulation, stem cell preparation technology, clinical application of stem cells and so on. Stem cell industry has become an infinite potential economic growth point, containing a great industry development space.

Tissue engineering is a discipline that applies the principles and methods of engineering and life science to study the structure, function and growth mechanism of mammalian tissues under normal or pathological conditions, and to develop artificial biological substitutes that can repair, maintain or improve damaged tissues.

About the boundary of stem cell and tissue engineering, we discuss them respectively as follows:

(1) The boundary of stem cells has a compete industrial chain, consisting of the upstream industry-stem cell collection and storage business, midstream industry-stem cell proliferation and stem cell preparation technology $\mathrm{R} \& \mathrm{D}$, downstream industry-stem cell transplantation, treatment and stem-cell industry integration with other industries.

(2) Among the industrial chain boundary of organization engineering, the most attractive prospect of stem cell technology is to grow some tissues and organs from stem cells as seed cells in vitro, which can be used to replace the aging and diseased tissues and organs of human body. Tissue engineering includes "tissue engineering of structural tissues and organs" and "tissue engineering of

\footnotetext{
*Corresponding authors: phs@szu.edu.cn
} 
metabolic tissues and organs". Structural tissues and organs include cartilage, bone, tendon, skin while metabolic organs such as liver, kidney, pancreas, heart, etc.

Though Guangdong province started cell research early in China, and has achieved certain achievements in fields such as induced pluripotent stem (iPS) cell technology and stem cell regulation, there is still a significant gap for Guangdong to catch up with developed countries. In view of the current situation, Guangdong province are suggested to make stem cells and tissue engineering industry technology roadmap of by analyzing the industrial chain and understanding the opportunities, advantages and challenges of stem cells and tissue engineering industry, so as to concentrate superior resources, provide short-, medium- and long-term technical guidance and support for the development of enterprises and industries.

\section{METHODS OF PREPARING TECHNOLOGY ROADMAP OF STEM CELL AND TISSUE ENGINEERING INDUSTRY}

To reach a higher-level of stem cells and tissue engineering industry, the methods are advised like analyzing the status quo, market demand, industrial and technical barriers in this field, finding future development direction along the "market demand analysis - industrial targets - technical barriers-development demand summary" path by pictures. Besides, planning the direction and the development process, achieving industry corresponding action plan and setting up production-study-research cooperation platform regionally and worldwide are also proposed.

\subsection{Basic steps for developing industry technology roadmap}

The technology roadmap is the combination of technology and market factors. Through the process of formulating the roadmap, the chaotic thinking is transformed into the implementation plan with clear positioning, and the divergent thinking leads to convergence and inheritance. The industrial technology roadmap consists of three stages of work (in figure 1): the preparation stage, the development stage, and the revision and implementation stage. The preparatory activities of the first stage are the starting stage, the second stage is the core part of formulation, and the third stage is about subsequent revision, which is also the process of continuous improvement. These three stages all adopt the scientific research method and each one has core work content.

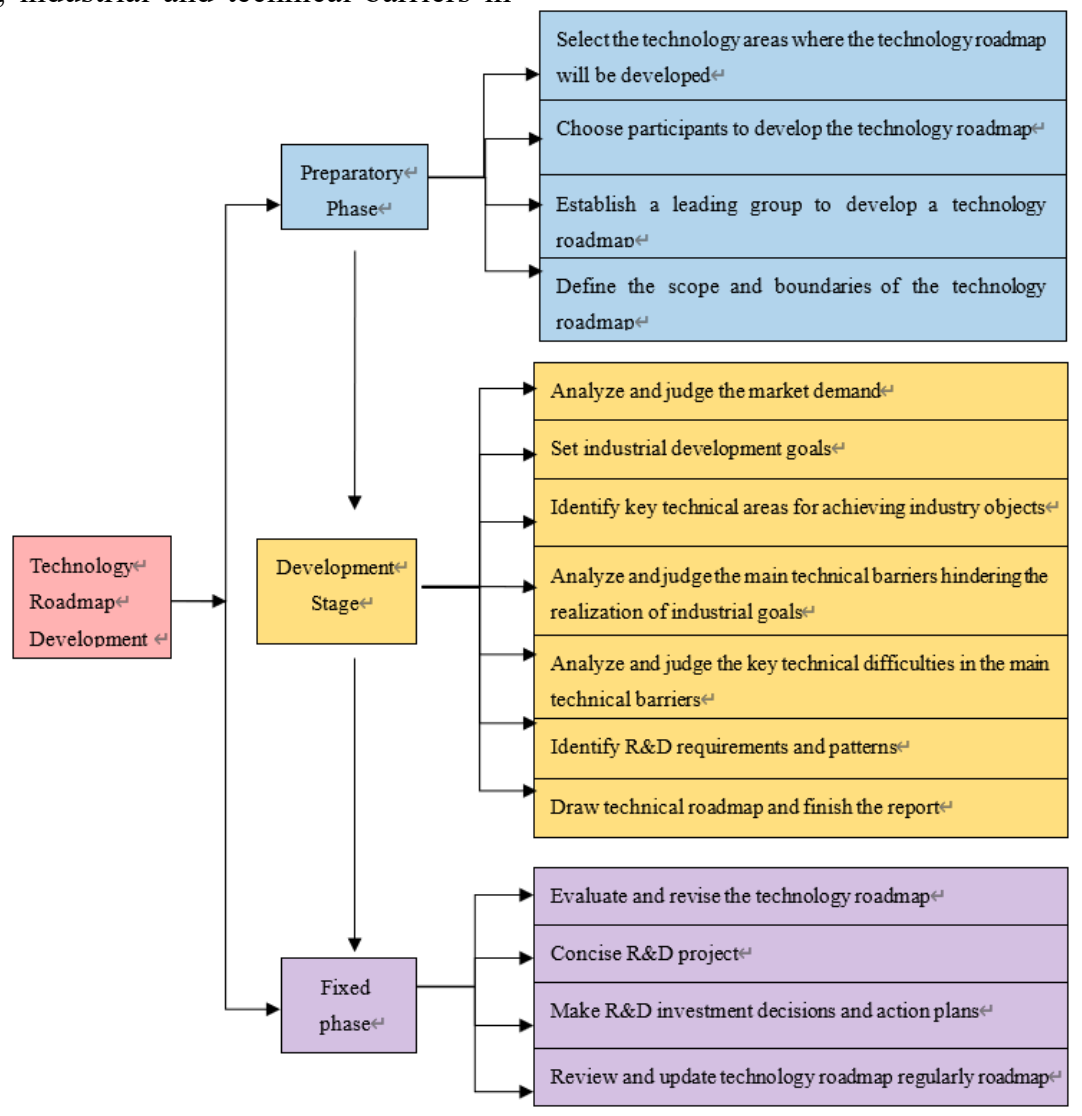

Figure 1. Basic steps and related contents of the industrial technology roadmap

\subsection{Methods and tools of correlated analysis}

The analytical methods and tools used in the process of formulating the industrial technology roadmap mainly include Delphi method, brainstorming method, comparative research method, and SWOT analysis method, etc. 

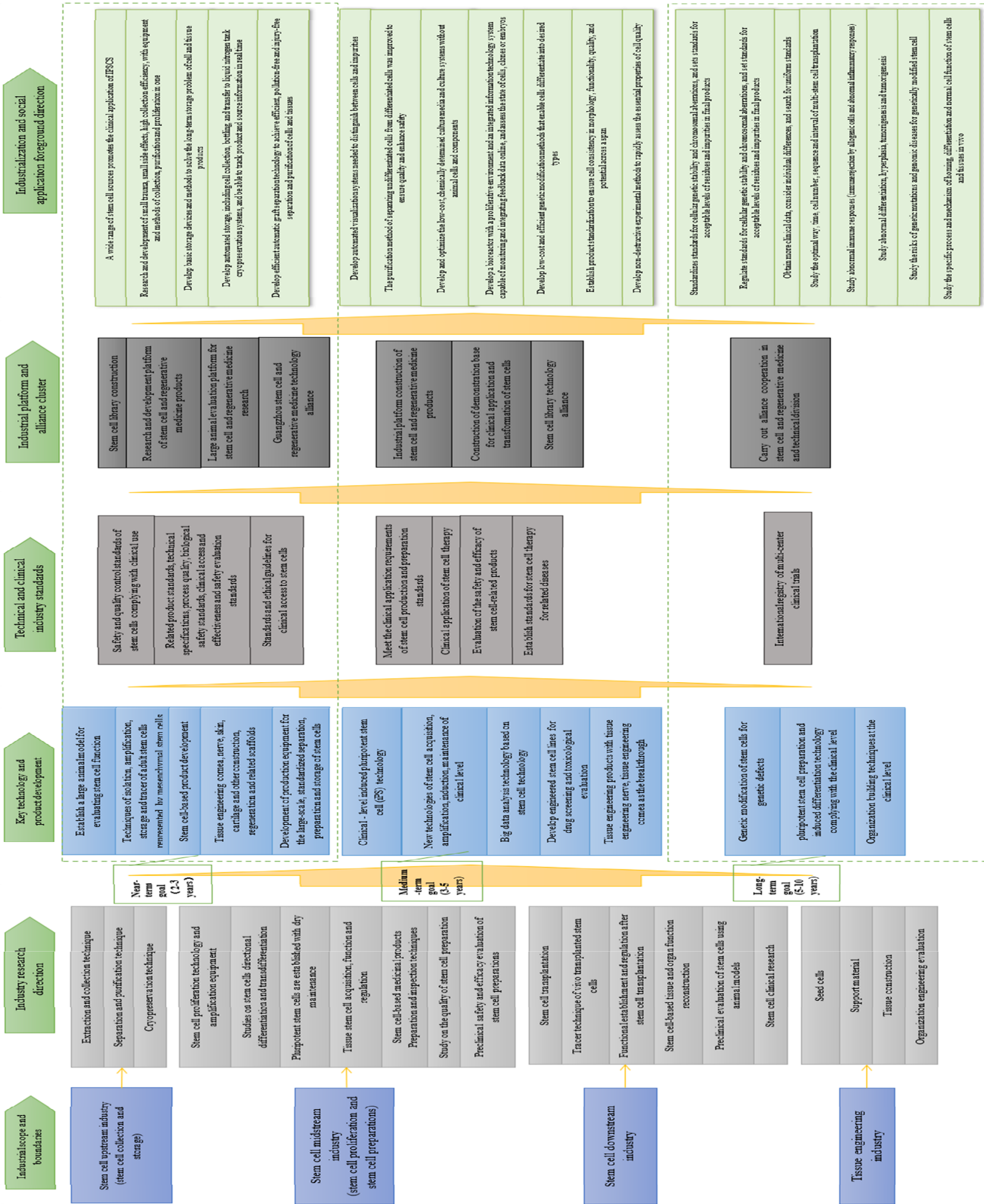

Figure 2. Technology roadmap of stem cell and tissue engineering industry

\section{SPECIFIC CONTENTS AND FORMULATIONS OF THE INDUSTRIAL TECHNOLOGY ROADMAP}

In extensive solicitation of experts' opinions among colleges, research institutions and related enterprises, this paper draws stem cells and tissue engineering industry technology roadmap (in figure 2). Main research content are related to disease types, such as diseases of the nervous system, blood system diseases, etc., as well as establishing the relevant functional stem cell technology platform under the condition of production good manufacturing practice (GMP), including cell preparation, storage, safety assessment technology, transplantation, treatment and other technology platforms. 
Core contents contain five components: key technology, technical standard, clinical application, product research and innovative carrier construction.

\subsection{The key technology}

It consists of four types of technologies: (1) conforming to the clinical level of pluripotent stem cell preparation and induced differentiation technology; (2) techniques of isolation, amplification, storage and tracer of adult stem cells represented by mesenchymal stem cells; (3)genetic modification of stem cells for genetic defects; (4)tissue building techniques at the clinical level.

\subsection{The technical standard}

There are two technical standard to be reached: meeting the clinical application requirements of stem cell production and preparation standards as well as establishing stem cell therapy standards for related diseases.

\section{3clinical application}

The application covers evaluating the safety and efficacy of stem cell-related products, treatment and other indicators in the disease treatment of neurological, blood system, liver and autoimmune, developing stem cell therapies for related diseases and carrying out clinical experiments.

\subsection{Product research}

The targeted products to be developed include engineered stem cell lines for drug screening and toxicological evaluation, tissue engineering products with tissue engineering nerve and cornea as breakthrough points and an instrument for the separation, preparation and storage of stem cells.

\subsection{Innovative carrier construction}

By constructing a stem cell library, developing R\&D and industrial platform of stem cell and regenerative medicine products, the innovative carrier will be constructed.

\section{APPLICATION PROSPECTS}

Through 5-10 years of efforts, it is targeted to build the innovative system of technology, design and supply chain management of stem cell and tissue engineering industry for the sustainable development in Guangdong province and establish the leading position in China in this field. Specific vision is as follows:

\subsection{Mapping the future of stem cell and tissue engineering technology}

The technology roadmap of the stem cell and tissue engineering industry in Guangdong province identifies the key technologies needed and achievable by the industry, recognizes the technology gap and determines the priority order of the technology development of the industry, which points out the direction for the technology development of the stem cell and tissue engineering industry and provides a path to achieve the vision.

\subsection{As a basis for decision making}

The technology roadmap reflects its influence of development route and technology on the industry. Therefore, it can be used as the basis for formulating industrial policies through policy preference. At the same time, the technology roadmap can also provide a basis for technology investment decisions, increase investment in the most promising scientific and technological areas of the industry, and avoid risky or unprofitable technology investment.

\subsection{Forming a good communication and cooperation mechanism}

The making process and results of the technology roadmap emphasize the participation of multi-agents, including industry departments, industry associations, enterprises, research institutes, universities and other relevant departments. It closely links industry stakeholders together through information communication, strategy sharing, so that the industry has more access to technology (such as international science and technology cooperation, technology transfer and diffusion), and forms a common desire by the industry-university-research strategic alliance to solve the common technical problems.

\subsection{Better identification and meeting requirements}

The technology roadmap is driven by "market driving", and technological innovation must meet the needs of enterprises' entering the future market. It will help the industry stakeholders to make common understanding of the changes in the economy, society and environment and obtain the market opportunities by technology application.

\section{ACKNOWLEDGMENTS}

Project Supported by scientific research project of Shaanxi University of Chinese Medicine (2017PY18),Philosophy and Social Science Project of Guangdong Province (No.GD18CTS03), Science and Technology Project of Guangdong Province (No. 2019A101002111), Shenzhen University Humanities and Social Science Youth Project (No.18QFC20), Project of Guangdong Provincial Library (No.GDTK1802), Project of Guangdong Administration for Market Regulation(Guangdong Intellectual Property 
Administration)- construction project of intellectual property operation center of key universities and scientific research institutes in Guangdong Province, Project of Shenzhen Administration for Market Regulationintellectual property big data platform construction project (universities of Shenzhen). Hongshen Pang and Can Lin are co-corresponding authors.

\section{REFERENCES}

1. Cao Y. 2004. Theory and practice of tissue engineering. Shanghai science and technology press, Shanghai, China. 3-8.

2. Dai T. 2012. Stem cell technology and industry development report. Science press, Beijing, China.

3. Li X. 2008. Industrial technology roadmap-innovation practice of Guangdong science and technology management. Guangdong science and technology press, Guangdong, China.

4. Zeng L, Sun Y. 2007. Principle and formulation of industrial technology roadmap. South China university of technology press, Guangdong, China.

5. Wang $M$ (2006). Stem cells and tissue engineering. Chongqing medical, (11):1990-1992.

6. Huangfu D, Osafune K, Maehr R, et al. Induction of pluripotent stem cells from primary human fibroblasts with only Oct 4 and Sox2. Nature biotechnology, 2008, 26(11): 1269-1275.

7. Aguirre A, Rubio ME, Gallo V. Notch and EGFR pathway interaction regulates neural stem cell number and self-renewal. Nature 2010;467(7313):323-327

8. Alexander Kohlmaier, Bruce A Edgar.2008. Proliferative control inDrosophila stem cells. Current Opinion in Cell Biology, 20: 699-706. 